This is an electronic reprint of the original article. This reprint may differ from the original in pagination and typographic detail.

Author(s): Gorelick, Sergey; Ylimäki, Tommi; Sajavaara, Timo; Laitinen, Mikko; Whitlow, Harry

Title: $\quad$ Development of a MeV ion beam lithography system in Jyväskylä

Year: $\quad 2007$

Version:

Please cite the original version:

Gorelick, S., Ylimäki, T., Sajavaara, T., Laitinen, M., \& Whitlow, H. (2007).

Development of a MeV ion beam lithography system in Jyväskylä. Nuclear Instruments and Methods in Physics Research Section B: Beam Interactions with Materials and Atoms, 260(1), 77-80. https://doi.org/10.1016/j.nimb.2007.01.260

All material supplied via JYX is protected by copyright and other intellectual property rights, and duplication or sale of all or part of any of the repository collections is not permitted, except that material may be duplicated by you for your research use or educational purposes in electronic or print form. You must obtain permission for any other use. Electronic or print copies may not be offered, whether for sale or otherwise to anyone who is not an authorised user. 


\title{
1. Development of a MeV ion beam lithography system in Jyväskylä
}

\author{
${ }_{3} \quad$ Sergey Gorelick ${ }^{\mathrm{a}, *}$, Tommi Ylimäki ${ }^{\mathrm{a}}$, Timo Sajavaara ${ }^{\mathrm{a}}$, \\ ${ }_{4} \quad$ Mikko Laitinen ${ }^{\mathrm{a}}$, Ananda Sagari A.R. ${ }^{\text {, }}$, Harry J. Whitlow ${ }^{\mathrm{a}}$ \\ ${ }_{5}{ }^{a}$ Department of Physics, P.O.Box 35, FIN-40014 University of Jyväskylä, Finland
}

6 Abstract

7 A lithographic facility for writing patterns with cyclotron beams is under develop8 ment for the Jyväskylä cyclotron. Instead of focusing and deflecting the beam with electrostatic and magnetic fields a different approach is used. Here a small rectangular beam spot is defined by the shadow of a computer-controlled variable aperture 1 in close proximity to the sample. This allows parallel exposure of rectangular pat2 tern elements of $5-500 \mu \mathrm{m}$ side with protons up to $6 \mathrm{MeV}$ and heavy ions $\left({ }^{20} \mathrm{Ne}\right.$, ${ }^{85} \mathrm{Kr}$ ) up to few $100 \mathrm{MeV}$. Here we present a short overview of the system under 4 construction and development of the aperture design, which is a critical aspect for all ion beam lithography systems.

Key words: $\mathrm{MeV}$ ion beam lithography, cyclotron, proximity aperture, proton

PACS: 01.52.+r, 06.60.Ei, 29.20.Hm, 81.40.Wx, 85.40.Hp, 87.80.-y

\section{Introduction}


1 electrostatic accelerators allows high spatial-density patterns to be written 2 with line-widths on a few tens of nm scale. Cyclotron beams generally have 3 higher energies, which enables pattern writing in thicker resists (up to $400 \mu \mathrm{m}$ 4 for $6 \mathrm{MeV}$ protons in PMMA) [10]). However, even if large beam currents 5 are available (up to 100's of $\mu \mathrm{A}$ ), the divergence is often large (about $1 \mathrm{mrad}$ ) 6 which implies it is not straightforward, to use a magnetic focusing or proximity 7 aperture approaches.

\section{Experimental set-up}

The system is shown schematically in Fig. 1. The size and shape of the beam spot is defined by a computer-controlled aperture system that can be positioned in close proximity $(0.3-20 \mathrm{~mm})$ from the sample surface. The size and divergence $(<0.7 \mathrm{mrad})$ of the beam impinging on the computer-controlled aperture is defined by a water-cooled $1 \mathrm{~mm}$ diameter Ta aperture located $1.78 \mathrm{~m}$ upstream close to the exit of the switching magnet. Focusing is carried out using a magnetic quadrupole pair further upstream. A fluorescent screen and Faraday cup as well as Si p-i-n diodes [12] are used for beam diagnostics and current measurement. 
1 The principle of the aperture system is shown in Fig. 1. The sample is mounted 2 on exchangeable sample holders that fit onto a computer-controlled $x-y-z$ stage 3 [13] that has $100 \mathrm{~nm}$ precision and approximately $1 \mu \mathrm{m}$ accuracy (Fig. 1(b) and 4 (c)). Two L-shaped aperture blades in close proximity to the sample surface 5 cast a rectangular shadow on the sample that defines the shape of the beam 6 spot on the surface. (Fig. 1(a)). Precise movement of each L-shaped blade in 7 the $X^{\prime}$ and $Y^{\prime}$ directions using linear motion stages [13] defines the vertical and

horizontal size of the aperture. One corner of the rectangular aperture remains in a fixed position, while the position of the other three corners depends on $X^{\prime}$ and $Y^{\prime}$. Then combination of the sample position $(x, y, z)$ and the computercontrolled aperture $\left(X^{\prime}, Y^{\prime}\right)$ allows rectangular pattern elements to be written over a $20 \times 20 \mathrm{~mm}$ field. The maximum side length of the rectangular pattern elements can be up to $500 \mu \mathrm{m}$ while the minimum side length is determined by the resist contrast and penumbra broadening. The apertures, sample stage and beam blanking are controlled with a LabView-control program.

The two L-shaped aperture blades are each made from two $100 \mu \mathrm{m}$ thick $8 \times 15$ mm Ta sheets. Each aperture blade must be sufficiently thick to completely stop the incident ions. Taking this thickness to be $R_{p}+2 \sigma_{p}$, where $R_{p}$ and $\sigma_{p}$ is the projected range and projected range straggling, respectively, allows patterning with our system up to $\sim 6 \mathrm{MeV}$ protons and a few hundred $\mathrm{MeV}$ heavy ions such as ${ }^{20} \mathrm{Ne},{ }^{85} \mathrm{Kr}$ (see Fig. 2). Comparison of the aperture thickness for stopping the beam and the range in PMMA (a typical resist material) in Fig. 2) shows that up to $400 \mu \mathrm{m}$ thick resist can be written with protons and $\sim 150 \mu \mathrm{m}$ for heavy ions. This is well-matched to the capabilities of the Jyväskylä cyclotron which can deliver ions up to $130 \mathrm{~A} / \mathrm{q}^{2} \mathrm{MeV}$. Ta was chosen as the aperture material because of the ease of working and its high Z, which 
1 presents a high Coulomb barrier to most ions (11 MeV for protons, $21 \mathrm{MeV}$

2 for ${ }^{4} \mathrm{He}, 87 \mathrm{MeV}$ for ${ }^{20} \mathrm{Ne}, 262 \mathrm{MeV}$ for $\left.{ }^{85} \mathrm{Kr}[14]\right)$. This is important in or3 der to minimize spurious exposure of the resist by charged reaction products 4 formed on the aperture edges, as well as undesirable neutron production as 5 well as activation of the resist itself. Proton irradiation of polymers with ener6 gies of $6 \mathrm{MeV}$, or lower, can result in production of short-lived ${ }^{13} \mathrm{~N}$ with a 9.96 7 minutes half-life. The cross-section at $6 \mathrm{MeV}$ for fusion reaction ${ }^{12} \mathrm{C}(\mathrm{p}, \gamma){ }^{13} \mathrm{~N}$ 8 well below the Coulomb barrier $(11 \mathrm{MeV})$ was estimated to be $6 \mu$ b based on a 9 quantum mechanical calculation using the parabolic potential approximation with a $5 \mathrm{MeV}$ curvature parameter [15].

Experiment showed edge-polishing of the Ta blades clamped in a metal polishing jig with 2000 grove $\mathrm{SiC}$ paper followed by diamond paste [16], resulted in an edge with better than $80 \mathrm{~nm}$ peak to valley deviation from straightness [17] over $3.6 \mathrm{~mm}$, measured with a profiler(Fig. 3). Presumably, this can be further improved using finer diamond paste or sputtering.

The penumbra broadening is presented in Fig. 4(b) for different aperture sample distances. Note that because of the aperture construction, the minimum separation, when the sample and last aperture blade are in contact, is 3 times the aperture thickness $(300 \mu \mathrm{m})$. Taking a realistic minimum gap of $600 \mu \mathrm{m}$ gives an edge penumbra broadening of $340 \mathrm{~nm}$. This value represents an upper limit and the actual broadening is expected to be smaller because of concentration of the beam along paraxial directions. Thermal heating of the computer controlled aperture is an important issue because thermal expansion limits the rate of pattern writing. The fluence required to expose PMMA corresponds to about $10^{14}$ of $2 \mathrm{MeV} \mathrm{H}^{+}$ions per $\mathrm{cm}^{-2}$ [18]. An exposure rate of one pattern element in $30 \mathrm{~s}$ requires $0.6 \mu \mathrm{A}$ of protons into a $1 \mathrm{~cm}^{2}$ area onto 
1 the first aperture and correspondingly a maximum heat load of $9.2 \mathrm{~mW}$ on 2 the second aperture. For zero thermal resistance between the L-shaped blades 3 and the mounting blocks, which are assumed to be cooled only by radiation, 4 the corresponding linear change in aperture size is $14 \mathrm{~nm}$ for $10 \mathrm{~mm}$ between 5 blade-tip and fixing point. The overall absolute accuracy of the patterns is 6 then set by the combined accuracy of the $\left(x\right.$ and $\left.X^{\prime}\right)$ and $\left(y\right.$ and $\left.Y^{\prime}\right)$ linear 7 motion slides and corresponds to $1.4 \mu \mathrm{m}$ over $20 \mathrm{~mm}$ with a precision of better 8 than $140 \mathrm{~nm}$. It should be noted that parallel exposure of an entire pattern 9 element rather than exposing pixel by pixel dramatically reduces the problem

of thermal drifts because the much faster writing speed, allows a significant reduction in beam current. At these exposure rates the beam is adequately blanked within $1.5-2 \mu \mathrm{s}$ by a TTL signal sent to the accelerator injection system [19].

Secondary and scattered particles from the aperture blade edges may to have degrade the pattern edge sharpness. No theoretical analysis was performed, however, pattern broadening due to the particles scattered by the aperture is believed on the basis of ref. [20] to be relatively small.

\section{Conclusions}

The new MeV ion beam lithography system being constructed at the Jyväskylä Cyclotron Laboratory is described. This system is based on a computer controlled aperture system that can simultaneously expose rectangular pattern elements up to $500 \mu \mathrm{m}$ side length over a $20 \times 20 \mathrm{~mm}^{2}$ field with low energy $(6 \mathrm{MeV})$ protons for proton beam writing or up to a few hundred MeV heavy ions (Ne, Ar) for ion track patterning. The minimum exposed feature size set 
1 by penumbra broadening is $\sim 400 \mathrm{~nm}$ for a $600 \mu \mathrm{m}$ proximity gap. The energy

2 (2-1300 MeV) and ion range (from hydrogen to gold) available from Jyväskylä

3 K130 cyclotron make the presented lithography setup a very versatile system.

\section{Acknowledgements}

5 This work was carried out under the auspices of the Academy of Finland 6 Centre of Excellence in nuclear and accelerator-based physics (Ref 213503).

\section{References}

8 [1] F. Sun, D. Casse, J.A. van Kan, R.Ge, F. Watt, Tiss. Eng. 10 (2004) 267.

9 [2] K. Ansari, J.A. van Kan, A.A. Bettiol, F. Watt, Appl. Phys. Lett. 85 (2004) 476.

10 [3] A.A. Bettiol, T.C. Sum, J.A. van Kan, F. Watt, Nucl. Instr. and Meth. 210 $11 \quad$ (2003) 250.

12

13

[4] T.C. Sum, A.A. Bettiol, S. Venugopal Rao, J.A. van Kan, A. Ramam, F. Watt, Proc. SPIE 5347 (2004) 160.

[5] J.A. van Kan, P.G. Shao, K. Ansari, A.A. Bettiol, T. Osipowicz, F. Watt, in press.

[6] H. Ottevaere, B. Volckaerts, J. Lamprecht, J. Schwider, A. Hermanne, I. Veretennicoff, H. Thienpont, Jap. J. Appl. Phys. 43 (2004) 5832.

[7] F. Munnik, F. Benninger, S. Mikhailov, A. Bertsch, P. Renaud, H. Lorenz, M. Gmur, Microelectronic Engineering 67-8 (2003) 96.

[8] H.J. Whitlow, M.L. Auželité, I.A. Maximov, J.A. van Kan, A. Bettiol and F. Watt. Nanotechnology 15 (2004) 223. 
1 [9] J.A. van Kan, A.A. Bettiol and F. Watt, Appl. Phys. Lett. 83 (2003) 1629.

2 [10] J.F. Ziegler, SRIM-2003, from http://www.SRIM.org

3 [11] S. Gorelick, P. Rahkila, A. Sagari A.R., T. Sajavaara, S. Cheng, L.B. Karlsson, $4 \quad$ J.A. van Kan, and H.J. Whitlow, Growth of bone-cells on lithographically modified $5 \quad$ surfaces, submitted.

6 [12] Si PIN photodiode S1223-01, http://www.hamamatsu.com

7 [13] ESP300 1-3 Axis Motion Controller/Driver, MFA-CCV6 Miniature Linear $8 \quad$ Stages, http://www.newport.com

9 [14] Spectrometer calculator of J. Kantele, "Practical" Columb barrier.

10 [15] PACE4 code, part of LISE++ software, D. Bazin, O. Tarasov, M. Lewitowicz, $11 \quad$ O. Sorlin, Nucl. Instr. and Meth. A 482 (2002) 307.

12 [16] Diamond \& tools PD0501/4HP, grain size 1/2-0 $\mu \mathrm{m}$.

13 [17] B46.1-2002 Surface roughness, waviness and lay, ISBN 0791828018.

14 [18] J.A. van Kan, J.L. Sanchez, B. Xu, T. Osipowicz, F. Watt, Nucl. Instr. and $15 \quad$ Meth. B 158 (1999) 179.

[19] E. Liukkonen, New K130 Cyclotron at Jyväskylä, in Proceedings on the 13th International Conference on Cyclotrons and their Applications, Vancouver 1992, pp. $22-27$.

[20] M.L. Taylor, R.D. Franich, A. Alves, P. Reichart, D.N. Jamieson, P.N. Johnston, Nucl. Instr. and Meth. B (2006), in press. 

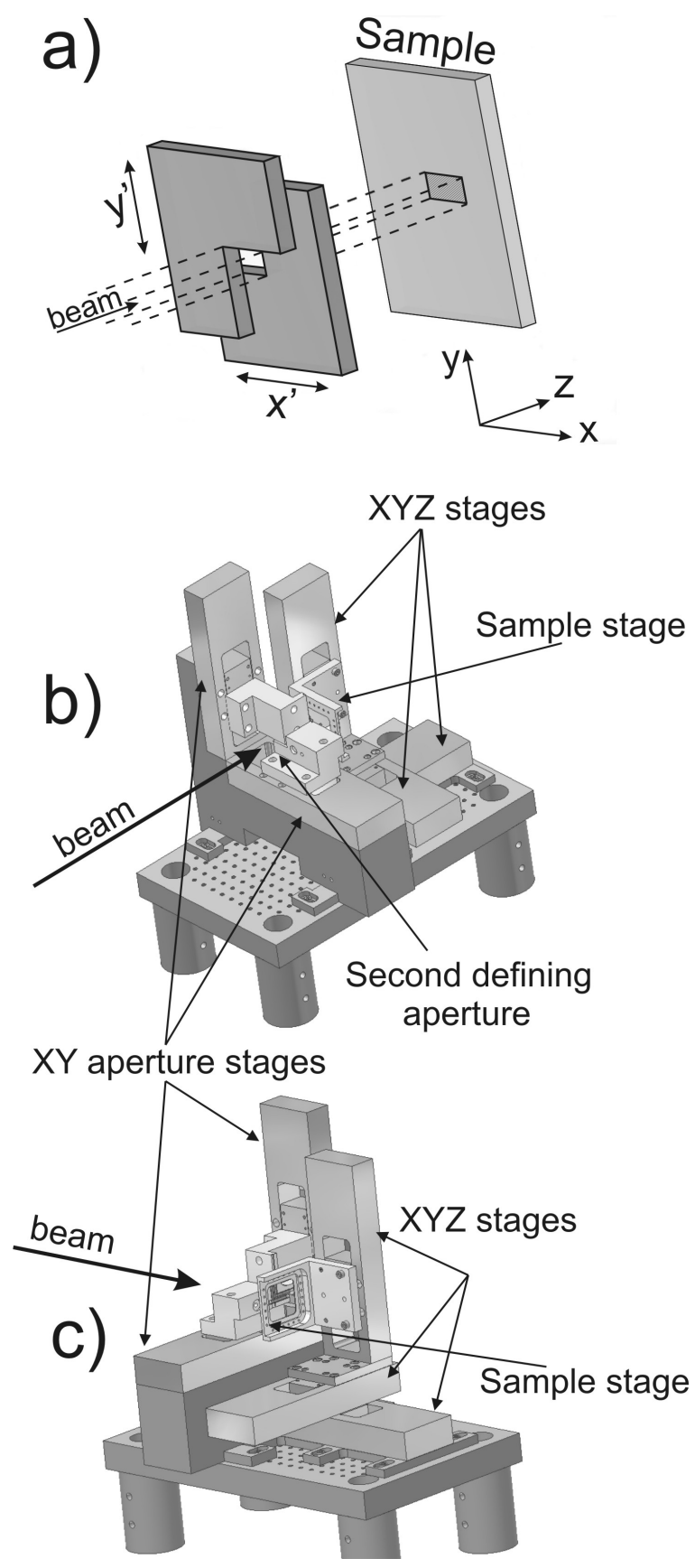

Fig. 1. Schematic layout of the ion beam lithography setup: The defining aperture. The opening of the aperture is controlled by relative motion of two tantalum L-shape plates. b) Aperture and sample are mounted on motorised stages. c) View from behind. 

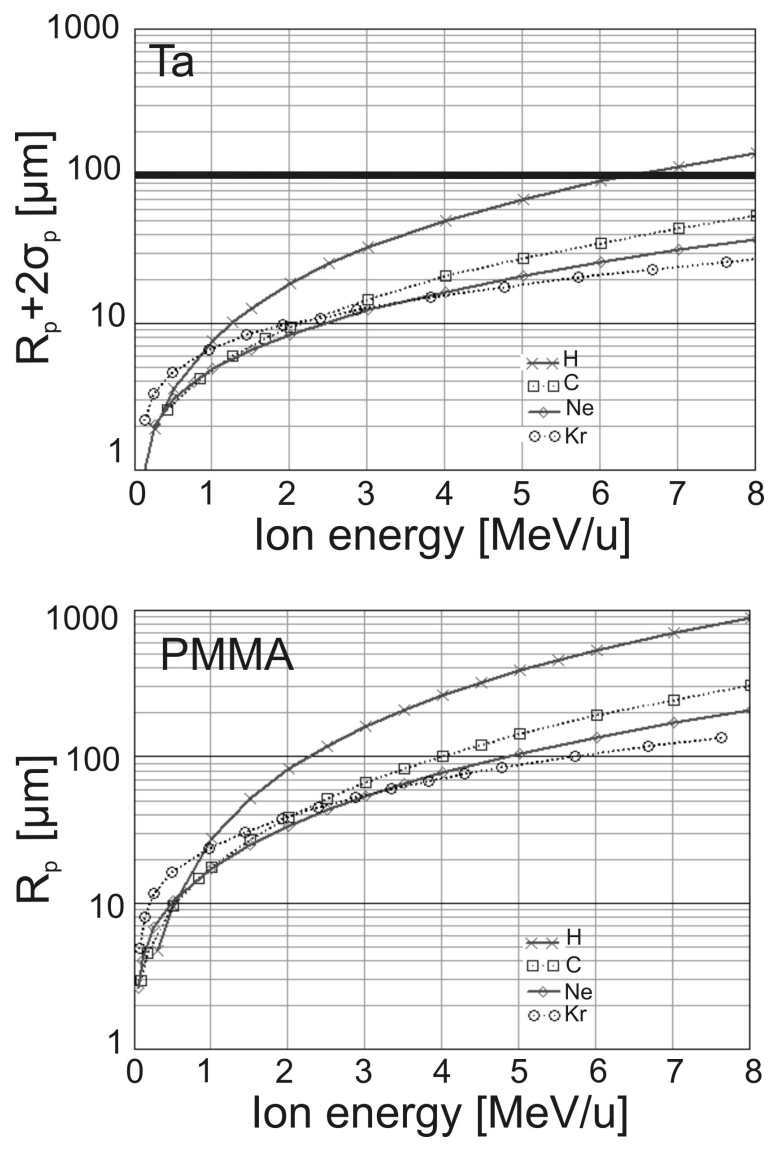

Fig. 2. $R_{p}+2 \sigma_{p}$ of different ions in Ta vs. ion energy (top), range for different ions in PMMA vs. ion energy (bottom) [10]. 


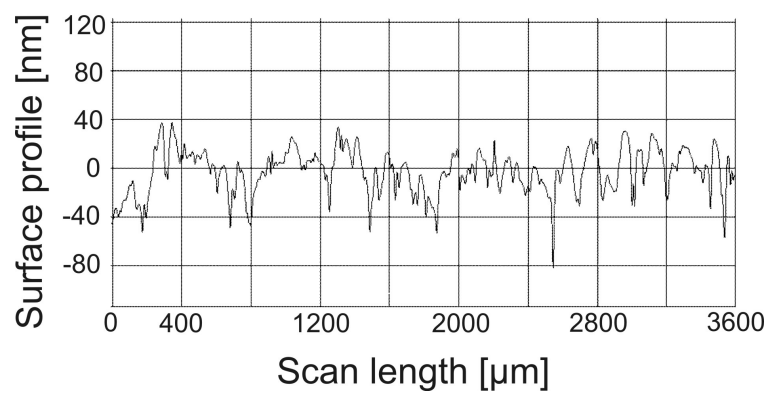

Fig. 3. Edge roughness of Ta aperture blade measured with a profiler after polishing with diamond paste. 


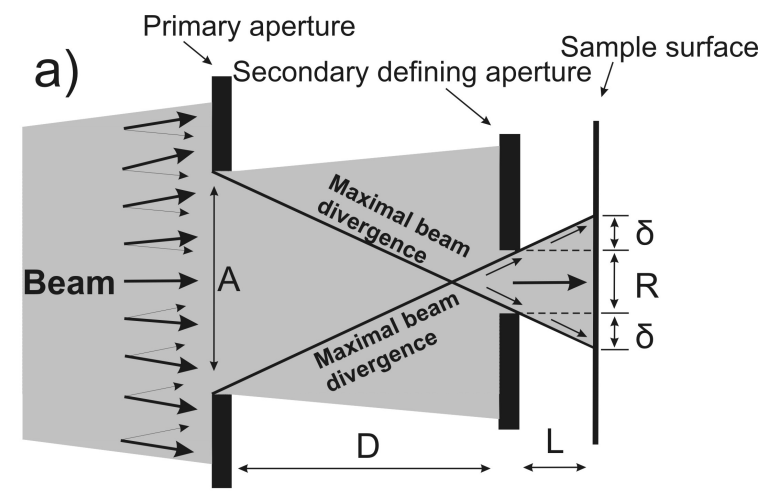

b)

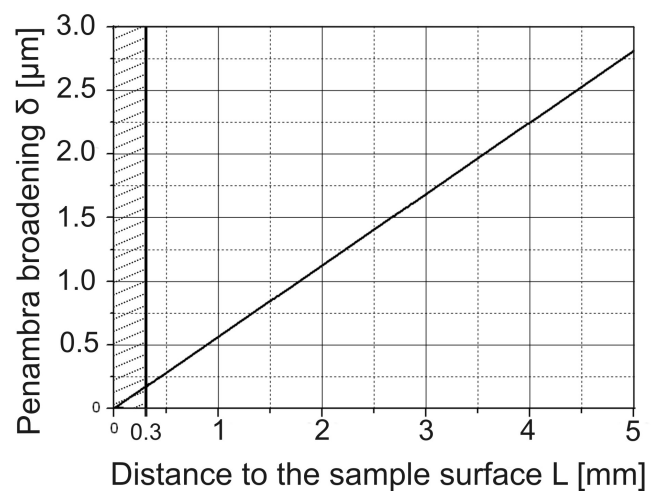

Fig. 4. a) Schematic of the collimation system. The primary aperture opening, $A$, is $1 \mathrm{~mm}$ in diameter, distance between the primary and the defining aperture, $D$, is $1.78 \mathrm{~m}, L$ is a distance between the sample surface the the defining aperture, and $R$ is the opening of the defining aperture. b) Penumbra broadening, $\delta$, for different proximity of the defining aperture to the sample surface. The shaded area denotes the forbidden distances resulting from the finite aperture blade thickness. 